\title{
REVERSAL AFTER LAPAROSCOPIC STERILISATION- A PRACTICAL APPROACH
}

\author{
Shallu Jamwal' ${ }^{1}$ Amit Manhas ${ }^{2}$,Kamlesh Manhas ${ }^{3}$
}

${ }_{1}^{1}$ Medical Officer, Jammu \& Kashmir Health Services, Jammu and Kashmir.

${ }^{2}$ Lecturer, Department of Urology Anaesthesia, SSH, GMC, Jammu.

3Senior Consultant, ASCOMS and Hospital, Sidhra, Jammu; Ex. Professor \& HOD, Department of Obstetrics \& Gynaecology, GMC \& ASCOMS, Jammu.

\section{ABSTRACT}

\section{BACKGROUND}

Female sterilisation has been widely accepted in India especially after the availability of endoscopic ligations and even the couples with low parity have started opting for it. As per ministry of health records, 46 lakh tubectomies were performed as against 1.79 lakh vasectomies between 2011 and 2012. Success of national sterilisation programme is possible only with universal availability of reversal procedures in the fast changing present day social scenario.

The aim of the study was to find an easy and practical approach for reversal after laparoscopic sterilisation and to devise an easy and universally available reversal procedure for the providers of sterilisation services.

\section{MATERIALS AND METHODS}

Twenty-five females presenting in OPD for reversal of laparoscopic sterilisation were counselled and operated abdominally using $4 \mathrm{x}$ magnification with a simple technique after ruling out infection under regional anaesthesia, i.e. combined spinal and epidural technique. The tissues were continuously irrigated with heparinised ringer lactate.

\section{RESULTS}

The common reason for reversal was death of one or more children in twenty cases. Other reasons for reversal were sickness of living children in two cases and remarriage in three cases. Patency was observed in all twenty-five cases at the time of operation. $16(64 \%)$ females conceived within 1-4 years. Out of these $14(56 \%)$ were term pregnancies and 2 (8\%) ended in abortions. 4 $(16 \%)$ did not conceive, whereas $2(8 \%)$ were lost to followup. The result of $3(12 \%)$ is still awaited. The type of anastomosis performed was isthmo-isthmic in 16 (64\%) with 9 term pregnancies and 1 abortion. 4 (16\%) were isthmo-ampullary with 2 term pregnancies and 2 with isthmo-interstitial cases had 2 term pregnancies. Combination of cornual implantation and isthmo-isthmic anastomosis in 1 case had a term pregnancy and 2 with combination of isthmo-isthmic and isthmo-ampullary anastomosis had 1 abortion.

\section{CONCLUSION}

The simplicity of the procedure, acceptable pregnancy rates and cost effectiveness as compared to IVF can contribute to benefit the masses especially located in remote areas and without the facility of latest techniques.

\section{KEYWORDS}

Laparoscopic Sterilisation Reversal.

HOW TO CITE THIS ARTICLE: Jamwal S, Manhas A, Manhas K. Reversal after laparoscopic sterilisation- A practical approach. J. Evolution Med. Dent. Sci. 2017;6(42):3324-3327, DOI: 10.14260/Jemds/2017/720

\section{BACKGROUND}

The national programmes to control the population and bring down the fertility rate has been going on for many years, but with the introduction of laparoscopy for sterilisation the acceptance of permanent method for sterilisation got boost and availability of facility in remote areas made it popular in masses. Most of the multiparous couples readily accepted it. In state of J\&K, laparoscopic sterilisation was started in 1980s and regular camps were organised along length and breadth of Jammu province, some remote areas were approached by army helicopters. Senior author of the study attended many such camps and witnessed many younger

Financial or Other, Competing Interest: None.

Submission 04-05-2017, Peer Review 15-05-2017,

Acceptance 19-05-2017, Published 25-05-2017.

Corresponding Author:

Dr. Shallu Jamwal,

House No. 249, Sector A,

Sainik Colony, Jammu-180011,

Jammu and Kashmir.

E-mail: drshallujamwal@gmail.com

DOI: $10.14260 /$ jemds $/ 2017 / 720$ couples with low parity reporting and requesting for laparoscopic sterilisation. However, it was not until mid-90s that request for reversal for ligation started.

About $0.2 \%$ of women after surgical tubal sterilisation request reversal procedure.(1),(2) The conventional reversal technique is microsurgical tubal anastomosis by laparotomy. In the study by Jindal et al,(3) applying microsurgical principles under $4 \mathrm{x}$ magnification $53.57 \%$ term pregnancies were achieved. The pregnancy rates after microsurgical tubal anastomosis are $45 \%$ to $82 \%$ and after laparoscopic anastomosis $25 \%$ to $73 \%$.(4) The success of these procedures depend upon multiple factors like method of prior sterilisation, site of anastomosis, length of reconstructed tube or tubes, status of tubes (presence or absence of adhesions), extent \& nature of adhesions \& presence of other pelvic disease, age of the patient \& other fertility factors especially of male partner.(5)

Pregnancy rates are lowest (49\%) after the reversal of sterilisation procedure involving unipolar electrocautery. In contrast, post-procedure pregnancy rates rose to $67 \%$ when the sterilisation technique involves Falope rings or spring loaded clips \& $75 \%$ when Pomeroy tubal ligation was employed.(6) 
In the absence of male factors, age of the female \& length of the reconstructed tube are important predictors of outcome.

Depending upon segments of the fallopian tube that are approximated, reversal procedure can be intramural isthmic, intramural ampullary, isthmo-isthmic, isthmo-ampullary, ampullo-ampullary or ampullary infundibular. Gentle tissue handling, proper haemostasis and keeping tissue moist are considered important during microsurgery. The best outcome is when anastomotic sites have no significant difference in tubal diameter (e.g. isthmo-isthmic or cornualisthmic anastomosis). Tubal length is also an important prognostic factor. Low pregnancy rates are associated with final anastomosed tubal length of less than $4 \mathrm{~cm} .{ }^{(6)}$

Surgical procedures for the reversal of sterilisation in the era of IVF may seem obsolete but with industrialisation of IVF the surgical art to train the residents and fellows might vanish and the fact remains that not many couples who opt for laparoscopic sterilisation at camps have access to medical institutes of the state or to the latest techniques. Since the state authorities post specialists in remote areas who could be trained in this simple reversal technique, a reasonable success rate would be expected.

\section{MATERIALS \& METHODS}

Twenty five females presenting in the OPD for reversal of laparoscopic sterilisation with falope rings were counselled and operated abdominally using $4 \mathrm{x}$ magnification with a simple technique after ruling out infection under regional anaesthesia, i.e. combined spinal and epidural technique using injection bupivacaine $0.25 \%$ via epidural catheter and $0.5 \%$ (heavy) in spinal anaesthesia.

A thorough preoperative evaluation included complete history (Especially address of patient, age of patient, duration of marriage, number of living children, year of laparoscopic sterilisation and its surgical details, reason for reversal, history of sexually transmitted disease, pelvic inflammatory diseases, vaginal discharge), menstrual history, obstetrical history, surgical history and detailed medical history of prolonged fever, cough, urinary tract infection or any other medical illness and medications. A through general physical and systemic examination followed by abdominal and per speculum examination for any cervical lesion or discharge, and bimanual examination done especially to rule out any adnexal mass or tenderness.

Investigations included semen analysis of the partner, haemoglobin, TLC, DLC, ESR, VDRL, HIV, HBsAg, Blood sugar, chest x-ray, USG Abdomen and pelvis and Pap smear.

Laparotomy evaluation was done to check for presence of ascites, adhesions of abdominal organs especially around liver to rule out Fitz Hugh-Curtis syndrome, condition of pelvic organs like uterus, tubes and ovaries and POD was noted along with presence of endometriosis and pelvic adhesions. Site of ring application, any abnormality of tube especially kinking or hydrosalpinx was noted.

Intra-operative irrigation is done with heparinised ringer lactate solution. This helped in periodic irrigation of exposed peritoneal surface \& to prevent desiccation \& to visualise individual bleeders.

The procedure was done under combined epidural and spinal anaesthesia with epidural catheter kept in epidural space-
- Abdomen opened by Pfannenstiel incision.

- Uterus, tubes \& ovaries delivered outside the incision and stabilised in this position by keeping packs in POD. $1 \mathrm{cc}$ solution (5000 units) of heparin in $500 \mathrm{cc}$ of ringer lactate used to irrigate tissues throughout the procedure.

- An opening made in mesosalpinx with cautery needle below ligation site, and sharp scissors used to cut the tube on either side of blocked portions (Fig. 1).

- 1-0 Ethilon threaded through fimbria to proximal end \& to uterus through cornual end (Fig. 2).

- Tubal anastomosis performed in 2 layers. In $1^{\text {st }}$ layer muscle was approximated with 4 stitches at $6,12,3$ \& 9 o'clock positions using 5-0 Vicryl.

- In $2^{\text {nd }}$ layer muscle and serosa apposed with 3 sutures at 12, 3 \& 9 o'clock with 5-0 Vicryl (Fig. 3).

- Tubal loops with Falope rings excised and rent in mesentery closed with 4-0 sutures.

- $\quad$ Threaded Ethilon gently pulled out \& packs removed (Fig. 4).

- $\quad$ Post-operatively steroids given along with antibiotics.

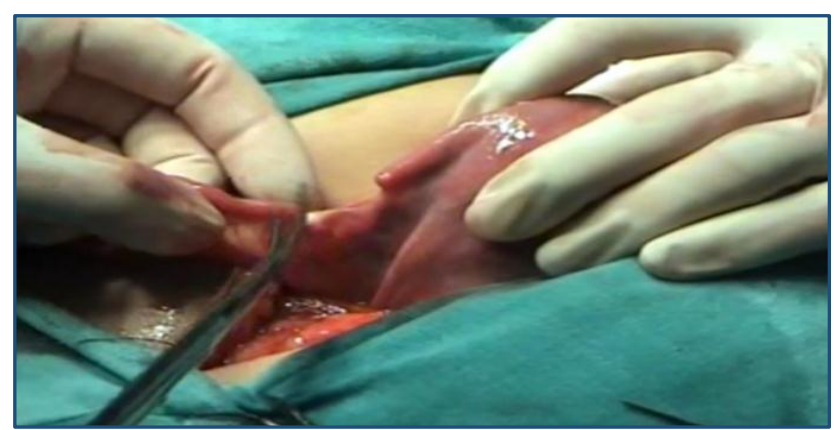

Figure 1

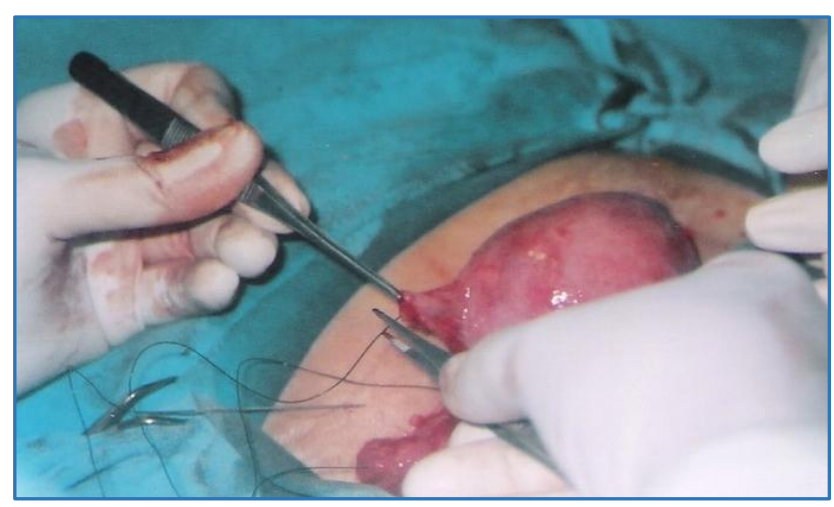

Figure 2

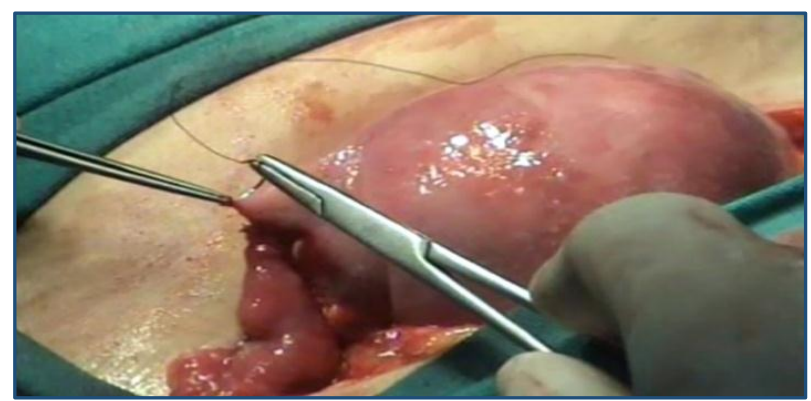

Figure 3 


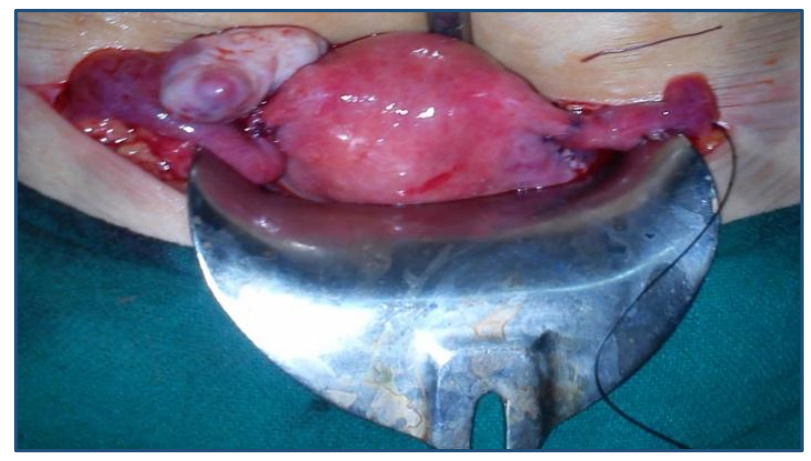

Figure 4

\section{RESULTS}

The study has been conducted on 25 females who requested for reversal of sterilisation. The study has included only cases of laparoscopic sterilisation using Falope rings.

Commonest reason for reversal was death of one or more children in $80 \%$ cases due to various reasons like accidents, drowning, snake bite, disease, etc. In $12 \%$ cases the reason was remarriage \& in another $8 \%$ cases because of sickness of living children.

All the cases had a thorough preparation and evaluation. At the time of laparotomy, no abnormal findings were detected and the uterus along with tubes and ovaries could be easily delivered out of incision and well stabilised in that position with packs kept in pouch of Douglas thereby extra handling was avoided and good operating field was obtained (fig-1). Cannulation could be performed in 24 cases and in 1 case cannulation could not be performed on one side through the cornual end.

All the conceptions were reported within 1-4 years, maximum within 1-2 years. Overall pregnancy rate was $64 \%$, with term pregnancy 14 cases (56\%) \& abortion in 2 cases $(8 \%), 4$ cases $(16 \%)$ did not conceive and 2 cases $(8 \%)$ were lost to followup. The result of 3 cases (12\%) is still awaited. The final length of the tubes was more than $5-6 \mathrm{~cm}$.

The type of anastomosis performed was isthmo-isthmic in 16 cases, isthmo-ampullary in 4 cases, isthmo-interstitial in 2 cases and combination of isthmo-isthmic with cornual implantation in 1 case and isthmo-isthmic with isthmoampullary in 2 cases.

The pregnancy achieved in isthmo-isthmic were 10 , out of which 9 were term pregnancies and 1 was abortion.

Out of 4 cases of isthmo-ampullary 2 term pregnancies were achieved.

In 2 cases of isthmo-interstitial anastomosis both had term pregnancies.

In 1 case on one side cornual implantation was done as the ring had been applied too close to cornu and on other side isthmo-isthmic anastomosis had been performed. LSCS was done at term.

In 2 cases a combination of isthmo-isthmic \& isthmoampullary anastomosis was done with pregnancy in one case who later had abortion.

\begin{tabular}{|c|c|}
\hline \multicolumn{2}{|c|}{ No. of Patients = 25 } \\
\hline Death of child/children & $20(80 \%)$ \\
\hline Remarriage & $03(12 \%)$ \\
\hline Sickness of child & $02(08 \%)$ \\
\hline Table 1. Reason for Reversal \\
\hline
\end{tabular}

\begin{tabular}{|l|l|}
\hline \multicolumn{2}{|c|}{ No. of Patients = 25 } \\
\hline Total Pregnancies & $16(64 \%)$ \\
• Term Pregnancies & $14(56 \%)$ \\
- Abortions & $02(08 \%)$ \\
\hline Not Conceived & $04(16 \%)$ \\
\hline Result Awaited & $03(12 \%)$ \\
\hline \multicolumn{2}{|c|}{ Table 2 } \\
\hline \multicolumn{2}{|c|}{$02(08 \%)$} \\
\hline
\end{tabular}

\begin{tabular}{|c|c|c|c|}
\hline $\begin{array}{c}\text { Type of } \\
\text { Anastomosis }\end{array}$ & $\begin{array}{c}\text { No. of } \\
\text { Pregnancies }\end{array}$ & $\begin{array}{c}\text { Term } \\
\text { Pregnancy }\end{array}$ & Abortion \\
\hline $\begin{array}{c}\text { Isthmo- } \\
\text { isthmic (16) }\end{array}$ & 10 & 09 & 01 \\
\hline $\begin{array}{c}\text { Isthmo-ampullary } \\
(04)\end{array}$ & 02 & 02 & 00 \\
\hline $\begin{array}{c}\text { Cornual } \\
\text { implantation \& } \\
\text { Isthmo-isthmic (1) }\end{array}$ & 01 & 01 & 00 \\
\hline $\begin{array}{c}\text { Isthmo- } \\
\text { isthmic \& Isthmo- } \\
\text { ampullary (2) }\end{array}$ & 01 & 00 & 01 \\
\hline $\begin{array}{c}\text { Isthmo- } \\
\text { interstitial (2) }\end{array}$ & 02 & 02 & 00 \\
\hline \multicolumn{3}{|c|}{ No. of Patients (n) = 25 } \\
\hline \multicolumn{2}{|c|}{ Table 3. Type of Anastomosis and Pregnancy Rate } \\
\hline
\end{tabular}

\section{DISCUSSION}

The study was conducted in 25 females after proper evaluation before and during surgery. A simple technique was used keeping in mind all the principles of surgery. The salient features of the present study have been obtaining a good operating field, avoiding instruments to steady the uterus with minimal tissue handling and keeping tissues moist throughout the procedure. The overall pregnancy rate of $64 \%$ was achieved.

Twenty-five patients who requested for reversal had undergone laparoscopic sterilisation with Falope rings. Lowest pregnancy rates (49\%) have been noted in reversal cases after unipolar electrocautery and $67 \%$ with application of Falope ring.(6)

In 20 cases, death of children due to various reasons like accidents, snake bite, drowning, disease, collapse of mud house were noted; sickness of living children in 2 cases and remarriage in 3 cases were the reason for reversal whereas other global reasons could be tsunami, earthquake, floods, terror attacks, etc.

In our study, death of children was commonest reason (80\%) for tubectomy reversal as compared to $64.28 \%$ in study conducted by Jindal et al(3) and $>70 \%$ in study by Premalatha $\mathrm{R}$ et al.(7)

In the present study, a thorough evaluation and workup was done to rule out any chronic systemic disease, pelvic inflammatory disease or any vaginal discharge by examination and investigations, if any, a complete treatment was instituted before surgery. Laparotomy evaluation was also done before surgery to rule out adhesions in abdomen especially around liver, Fitz-Hugh-Curtis syndrome, pelvic endometriosis, condition of pelvic organs and site of Falope ring and accordingly surgery was planned. 4x magnification was used. Good working field and exposure was obtained by stabilising the uterus and tubes outside the incision without 
the use of instruments (fig. 1). Tubes were divided with single sharp cut which helps in good apposition. The bisected segments were brought together and anastomosed perfectly with Ethilon threaded through the tube. This also helped in checking the patency of the tubes till the cornual ends at the time of surgery. Heparinised solution irrigation throughout the procedure kept the tissue moist. Combination of spinal and epidural anaesthesia gave a comfortable operating time. In the present study, the overall pregnancy rate was $64 \%$ with term pregnancy in 56\% (14/25) and abortion in $8 \%$ $(2 / 25)$ cases. In a study by Jindal et al,(3) term pregnancies were $53.57 \%(15 / 28)$ and abortion and ectopic gestation were $3.57 \%(1 / 28)$ each. Incidence of pregnancies was $<40 \%$ in a study by Premalatha $\mathrm{R}$ et al,(7) $60 \%$ by Trussel et al(8) and $60 \%$ by Silber et al.(6) $4 \%$ ectopic pregnancies were reported by Silber et al.(6) In the present study, there was no ectopic pregnancy.

Boeckxstaens et al(9) in their retrospective study of 163 women found surgery more economical than IVF and observed cumulative delivery rate of $52 \%$ at 72 months in the IVF group and $59.5 \%$ in the reversal group.

In present study, in 16 cases isthmo-isthmic anastomosis was performed and 10 conceptions resulted with nine term pregnancies and abortion in one. The equal calibre of the lumen on either side in isthmo-isthmic anastomosis gives good apposition and the same is true of cornual-isthmic anastomosis.(6) In our study, there were two cases of isthmointerstitial anastomosis and one case of combination of cornual implantation and isthmo-isthmic anastomosis and all the three cases had term pregnancies. The length of tube in our study was more than 5 to $6 \mathrm{~cm}$ after anastomosis. Less than $4 \mathrm{~cm}$ length of anastomosed tube can reduce the chances of pregnancy.(6)

\section{CONCLUSION}

The study was conducted in twenty five females seeking reversal of laparoscopic sterilisation after proper evaluation before and during surgery. A simple technique using $4 \mathrm{X}$ magnification under regional anaesthesia was used keeping in mind all the principles of surgery. The salient features of the present study were obtaining a good operating field, avoiding instruments to stabilise the uterus and tubes, minimal handling of the tissues and keeping them moist throughout the procedure. Overall pregnancy rate of $64 \%$ and term pregnancy rate of $56 \%$ was achieved.

Thus, the study concludes that reversal after laparoscopic sterilisation performed with $4 \mathrm{x}$ magnification is a simple, economical and reasonably successful technique with comparable results for the benefit of gynaecologists with less resources or expertise of tertiary centres.

\section{REFERENCES}

[1] Te velde ER, Boer ME, Looman CW, et al. Factors influencing success or failure after reversal of sterilization: a multivariate approach. Fertil Steril 1990;54(2):270-7.

[2] Wilcox LS, Chu SY, Peterson HB. Characteristics of women who considered or obtained tubal reanastomosis: results from a prospective study of tubal sterilization. Obstet Gynecol 1990;75(4):661-5.

[3] Jindal P, Gill BK, Gupta S. Reversal of tubal ligation under $4 \mathrm{x}$ magnification. $\mathrm{J}$ Obstet Gynecol India 2005;55(5):448-50.

[4] Afsoon Z, Wadha AG, Togas T. Tubal surgery. Clinical Obstetrics and Gynaecology 2009;52(3):344-50.

[5] Jonathan BS. Berek and Novak's gynaecology. Chapter 7. $14^{\text {th }}$ edn. Lippincott Williams and Wilkins 2007;30: 1185-275.

[6] Silber SJ, Cohen R. Microsurgical reversal of female sterilization: the role of tubal length. Fertil Steril 1980;33(6):598-601.

[7] Premalatha R, Tripathi MS. A study on the reversal of sterilisation in women over two decades. The journal of obstetrics and gynaecology of India 2012;62(1): 62-7.

[8] Trussell J, Guilbert E, Hedley A. Sterilisation failure, sterilisation reversal and pregnancy after sterilization reversal in Quebec. Obstet Gynecol 2003;101(4):67784.

[9] Boeckxstaens AN, Devroey P, Collins J, et al. Getting pregnant after tubal sterilization: surgical reversal or IVF? Hum Reprod 2007;22(10):2660-4. 